\title{
Efficacy of cognitive-behavioral therapy for insomnia: Implementation of a group format in the Spanish National Health System
}

\author{
Paula Lantarón-Imedio ${ }^{1}$, M. Rosario Pina-Camacho ${ }^{2}$, Marcos L. Moya-Diago ${ }^{2}$, Belén Pascual-Vera $^{3}$, \\ César Mateu $^{2}$, Elvira García-Trilles ${ }^{2}$ and Carmen Carrió ${ }^{2}$ \\ ${ }^{1}$ Hospital Universitario Infanta Elena, Madrid, Spain. \\ ${ }^{2}$ Hospital Arnau de Vilanova-Llíria, Valencia, Spain. \\ ${ }^{3}$ Universidad Nacional de Educación a Distancia (UNED), Madrid, Spain.
}

\begin{abstract}
Cognitive-behavioral therapy for insomnia (CBT-i) is considered the treatment of choice for this disorder, but it is not widely implemented in clinical settings. This study aims to examine the efficacy of a group format of CBT-i in the Spanish National Health System. Fifty-two participants with a primary insomnia disorder $\left(55.8 \%\right.$ women; $\left.M_{\text {age }}=47.19, S D=11.02\right)$ were assigned to a CBT-i $(n=17)$ or waiting list condition $(n=21)$. Treatment consisted of eight group therapy sessions ( 2 hours/week). Significant improvements in insomnia severity, sleep quality, and insomnia-related dysfunctional beliefs and attitudes were observed in patients who received CBT-i. Emotional symptoms also decreased after the intervention in the CBT-i group. Findings support the efficacy of a group protocol of cognitive-behavioral therapy for insomnia with a group protocol for patients with primary insomnia disorder. We also suggest a role of insomnia-related dysfunctional beliefs and attitudes in the maintenance of this disorder.
\end{abstract}

Keywords: insomnia; cognitive-behavioral therapy for insomnia; sleep disorders; dysfunctional beliefs; emotional disorders.

Eficacia de la terapia cognitivo-conductual para el insomnio: Una aplicación grupal en el Sistema Nacional de Salud Español

Resumen: La terapia cognitivo-conductual para el insomnio (TCC-i) es considerada como el tratamiento de elección para este trastorno, aunque su implementación en contextos clínicos no está lo suficientemente extendida. Este estudio pretende examinar la eficacia de la TCC-i, en formato grupal, en el Sistema Nacional de Salud español. Cincuenta y dos participantes con un diagnóstico de Trastorno de Insomnio Primario (55.8\% mujeres; $\left.M_{\text {edad }}=47.19, D T=11.02\right)$ fueron asignados a la condición de TCC-i $(n=17)$ o de lista de espera $(n=21)$. El tratamiento consistió en ocho sesiones grupales ( 2 horas/semana). Se observaron mejorías significativas en la gravedad del insomnio, la calidad de sueño y en las creencias y actitudes disfuncionales relacionadas con el insomnio, en aquellos pacientes que recibieron la TCC-i. Los síntomas emocionales también disminuyeron tras la intervención en el grupo de TCC-i. Los hallazgos apoyan la eficacia de la terapia cognitivo-conductual para el insomnio en un formato grupal para pacientes con trastorno de insomnio primario. Se sugiere el rol de las creencias y actitudes disfuncionales relacionadas con el insomnio en el mantenimiento de este trastorno.

Palabras clave: insomnio; terapia cognitivo-conductual para el insomnio; trastornos del sueño; valoraciones disfuncionales; trastornos emocionales.

Recibido: 15 de enero de 2021; aceptado: 11 de junio de 2021.

Correspondence: Paula Lantarón Imedio, Servicio de Salud Mental, Hospital Universitario Infanta Elena, Av. de los Reyes Católicos, 21, 28342 Valdemoro, Madrid, España. E-mail: pau.lantaron@gmail.com. 


\section{Introduction}

Insomnia is an important public health problem due to its high prevalence and comorbidity with other disorders. One-third of the general population suffer from insomnia symptoms and around $10 \%$ meet the criteria for insomnia disorder (Baglioni et al., 2019; Morin et al., 2006; Ohayon, 2002). Insomnia is highly comorbid with chronic illnesses (e.g., cardiovascular disease, obesity, hypertension) and mental disorders, such as depression. Experts in this area propose that the relationship between insomnia and depression could be bidirectional because $67 \%$ of patients diagnosed with major depression also meet the diagnostic criteria for insomnia (e.g., Baglioni et al., 2011; Franzen \& Buysse, 2008), and, conversely, insomnia disorder is considered a risk factor for depression (e.g., Ashworth et al., 2015).

The major role of psychological factors in insomnia has been extensively supported. Current cognitive models (e.g., Edinger \& Means, 2005; Harvey, 2002; Perlis et al., 2009) postulate that cognitive dimensions (i.e., intrusive thoughts, worry) and dysfunctional behaviors, such as safety behaviors and other compensatory behaviors, may be etiopathogenic factors of insomnia. A question that arises is whether dysfunctional beliefs related to sleep and insomnia might also play a role in insomnia maintenance. In a pioneer study, Morin et al. (1993) observed that subjects with insomnia had more dysfunctional beliefs and attitudes than subjects without insomnia. Their study showed that beliefs about the consequences of insomnia, loss of control, and prediction of sleep differentiate between insomniac and non-insomniac individuals. Similarly, Edinger et al. (2000) found that these beliefs were also associated with the severity of insomnia and distress. Regarding treatment, Edinger et al. (2001) observed greater reductions in dysfunctional sleep-related beliefs in patients with primary insomnia who received CBT, compared to patients who received a relaxation treatment or a placebo. These results were replicated by Morin et al. (2002), who found that dysfunctional beliefs were reduced only in individuals receiving CBT. Improvements of these dimensions were also associated with subjective ratings of sleep (e.g., restedness, sleep quality) at six-month follow-up (Edinger et al., 2001) and with subjective sleep efficiencies in two-year follow-up periods (Morin et al., 2002). Finally, the recognition of the key role of these dimensions has been supported by the efficacy and effectiveness of cognitivebehavioral therapy for insomnia (CBT-i) in the treatment of insomnia disorder (e.g., Sibern \& Manber, 2011, van Straten et al., 2018; Wilson et al., 2010), insomnia as a comorbid symptom (e.g., Geiger-Brown et al., 2015; Sadler et al., 2018), and depressive symptoms (e.g., Gee et al., 2019; Ballesio et al., 2018).

Although the efficacy of CBT for insomnia has been well established, as well as the role of cognitive mediators in the maintenance of this disorder, the implementation of CBT-i interventions in clinical settings is not as widespread as might be expected (e.g., Baglioni et al., 2019). Bearing this in mind, the purpose of the current study is to examine the efficacy of a group CBT-i format in patients with primary insomnia disorder receiving care in the Spanish National Health System. The intervention includes cognitive therapy components especially designed to address dysfunctional sleep-related beliefs and attitudes, and the present study aims to analyze the effects of the intervention on these dimensions.

\section{Method}

\section{Participants}

Fifty-two individuals with a diagnosis of primary insomnia disorder were assigned to two conditions: waiting list (WL; $n=22)$ and CBT-i group $(n=30)$. Among them, $55.8 \%$ were women $(n=29)$, and the mean age was 47.19 years $(S D=11.02$; range: 18 to 64 years). Participants did not differ in gender distribution $\left(\chi^{2}=0.692 ; p=.405\right)$, and women and men had a similar mean age $(t=-0.717 ; p=.477)$. The majority of the participants were married/cohabiting $\left(\chi^{2}=\right.$ 29.692; $p<.001)$, employed $\left(\chi^{2}=60.154 ; p<.001\right)$, had a medium socio-economic status $\left(\chi^{2}=52.137 ; p\right.$ $<.001)$, and medium education levels $\left(\chi^{2}=9.962 ; p\right.$ $=.007)$. Of this initial sample, 38 patients completed the treatment: WL: $n=21$ and CBT-i: $n=17$. The two groups of participants were comparable with regard to the duration of the disorder, their use of insomnia drugs, and socio-demographic variables, as shown in Table 1.

\section{Procedure}

The study participants were recruited by healthcare professionals in three outpatient services located in Arnau de Vilanova Hospital (Valencia, Spain): Neurophysiology, Mental Health, and Primary Care. The study recruitment took place from April 2017 to December 2019. Inclusion criteria were: (a) having a primary insomnia disorder diagnosis; (b) being 18 to 65 years old; and (c) availability to attend the treatment sessions. The exclusion criteria were as follows: (a) having a comorbid mental disorder (excluding anxiety and depression symptoms); (b) having an intellectual disability or a level of illiteracy that could 
Table 1. Differences between WL and CBT-i patients in duration of insomnia, medication, and demographic variables

\begin{tabular}{|c|c|c|c|c|}
\hline Measures & $\begin{array}{c}\mathrm{WL} \\
(n=21)\end{array}$ & $\begin{array}{c}\text { CBT-i } \\
(n=17)\end{array}$ & $\chi^{2 / t}(d f)$ & $p$ \\
\hline Months of evolution & $141.6(130.6)$ & $144(146.6)$ & $-0.053(36)$ & .958 \\
\hline Insomnia-drugs $(\%)$ & 47.6 & 58.8 & 0.473 & .492 \\
\hline Age & $48.9(11.2)$ & $42.6(11.1)$ & $1.748(36)$ & .089 \\
\hline Female $(\%)$ & 57.1 & 52.9 & 0.67 & .796 \\
\hline Employed (\%) & 71.4 & 82.4 & 2.980 & .395 \\
\hline Married/cohabiting (\%) & 47.6 & 52.9 & 0.919 & .821 \\
\hline Medium socio-economic level (\%) & 70.0 & 82.4 & 5.795 & .122 \\
\hline Medium educational level (\%) & 33.3 & 58.8 & 2.608 & .271 \\
\hline
\end{tabular}

Note: WL: waiting list; CBT-i: cognitive-behavioral therapy for insomnia.

interfere with following the treatment; and (c) having a medical illness such as hyperthyroidism, sleep apnea, chronic pain, and/or restless leg syndrome. Patients were individually screened by one of the authors (all clinical psychologists).

Potential participants were contacted by phone before the assessment session. Intake assessment consisted of the Mini International Neuropsychiatric Interview (MINI, Sheehan et al., 1998) and an ad-hoc semi-structured interview to determine current disorder diagnoses. Information about basic demographic data (e.g., age, gender, marital status), characteristics of insomnia, and current/past psychological or pharmacological treatments were recorded. Further information about the purpose of the study and the treatment protocol was provided. Before being included in the study, all potential participants were asked for their explicit consent to participate. After giving his or her explicit signed consent, each patient was given a questionnaire packet containing the self-report questionnaires described in the instruments section.

As shown in Figure 1, a total of 147 patients were referred, and 52 were included in this study. Patients

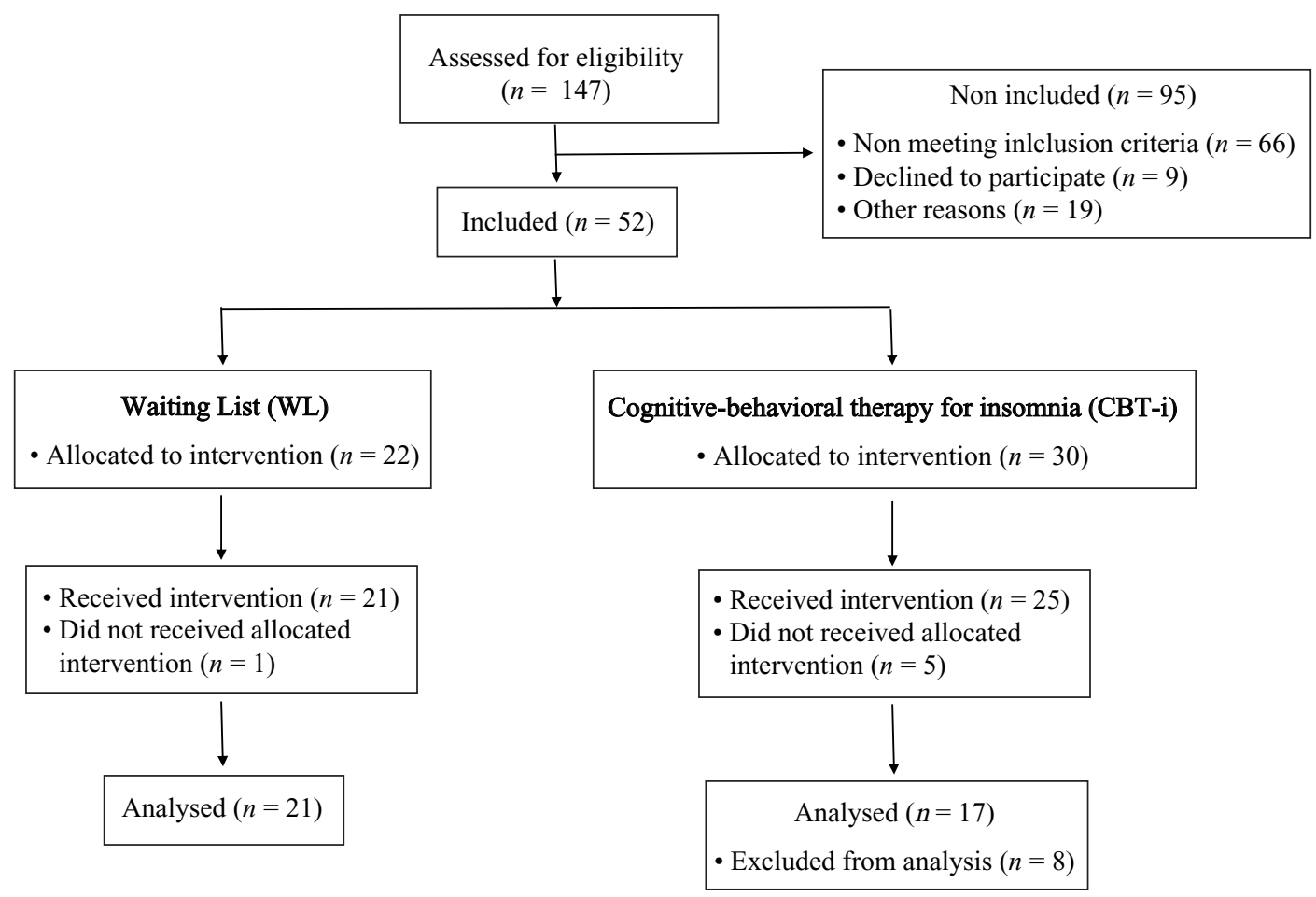

Figure 1. Flow diagram of the recruitment, allocation and data analyses. 
were randomly assigned to each group using a waiting list protocol. The current study was approved by the Ethics Committee of Clinical Investigation at Arnau de Vilanova Hospital (Valencia, Spain).

\section{Instruments}

For the self-report questionnaire measures described below, published Spanish translations following the established norms were used.

Insomnia Severity Index (ISI; Bastien, Vallières \& Morin, 2001). It is a 7-item self-report questionnaire that evaluates the severity of insomnia during the past month. The total score ranges from 0 to 28 , and in this study, Cronbach's alpha was .58.

Pittsburgh Sleep Quality Index (PSQI; Buysse et al., 1989). This self-report questionnaire is composed of 19 items that assess sleep alterations and quality during the past month. In this study, only the total score was used (ranging from 0 to 21), and the Cronbach's $\alpha$ value was 55 .

Dysfunctional Beliefs and Attitudes about Sleep Scale (DBAS; Morin et al., 1993, 1994). This is a 30-item questionnaire designed to assess beliefs, attitudes, attributions, and expectations about sleep and insomnia. It is composed of five dimensions and a total score (ranging from 30 to 150). Scores are interpreted inversely, so that lower scores indicate more dysfunctional attitudes and beliefs. In this study, the reliability values ranged between low and acceptable: consequences of insomnia $\alpha=.68$; control of sleep $\alpha=.51$; sleep requirement expectations $\alpha=.38$; causal attributions of insomnia $\alpha=.49$; sleeppromoting practices $\alpha=.47$; and total score $\alpha=.72$.

Epworth Sleepiness Scale (EES; Johns, 1991). This self-report scale evaluates the tendency to fall asleep in different situations distributed through 8 items on the instrument. The total score ranges from 0 to 24 , and the Cronbach's $\alpha$ value was .72.

Beck Depression Inventory-II (BDI-II; Beck et al., 1996). It is a 21-item self-report questionnaire that assesses the severity of depressive symptoms. The total score ranges from 0 to 63 , and the internal consistency was good: $\alpha=.88$.

Beck Anxiety Inventory (BAI; Beck \& Steer, 1993). It is a self-report measure composed of 21 items that evaluate the severity of anxiety symptoms in the past week. Cronbach's alpha was .89 .

\section{Treatment}

CBT for insomnia was structured by the authors following the guidelines by Perlis et al. (2009) guidelines.
The treatment protocol consisted of 8 sessions over a 10week period in a group format with 5 to 10 participants. Sessions were held 2 hours per week, except the $2^{\text {nd }}$ and $8^{\text {th }}$ sessions, which were biweekly (two hours per two weeks). Components used were psycho-education, sleep restriction, cognitive restructuring of dysfunctional attitudes and beliefs about sleep, and relapse prevention. Sessions were conducted by a therapist and co-therapist, who were also supervised by a clinical psychologist.

\section{Statistical analysis}

An alpha level of .05 (two-tailed) was used for all statistical tests. The effects of the intervention were examined using a 2 (group) x 2 (time) mixed ANOVA. The within- subjects factor was the time of assessment (two levels: pre vs. post-treatment), and the betweengroups factor was the sample group (two groups: WL vs CBT-i), with the dependent variables being the insomnia dimensions and the emotional symptoms. Preliminary analysis revealed that the homogeneity of covariances assumption was violated. Considering the homogeneity of variances, the sample size and equivalence between groups, and the sensitivity of Box's statistic, ANOVAs were performed (Pituch \& Stevens, 2015). Post hoc analyses and effect sizes $\left(\eta^{2}\right)$ were calculated. Data was analyzed using IBM SPSS Statistics (22).

\section{Results}

\section{Treatment effects: Between- and within-group differences in insomnia dimensions and emotional symptoms}

Table 2 displays between- and within-group differences in insomnia dimensions and emotional symptoms. The ANOVA results showed main effects for the sample group (WL vs. CBT-i) and time of assessment (pre vs. post-treatment) on most of the target variables. Moreover, an interaction effect between the time of assessment and the sample group was also observed, indicating that severity of insomnia, sleep quality, and dysfunctional insomnia beliefs and attitudes differed between WL and CBT-i participants in the pre and post-assessments. The effect sizes $\left(\eta^{2}\right)$ were between medium and high.

At the between-group comparison level (i.e. WL group vs. CBT-i), results showed that both WL and CBT- $\mathrm{i}$ participants scored similarly at pre-treatment, whereas after the intervention, the CBT-i patients scored lower on severity of insomnia and dysfunctional sleep-related beliefs and attitudes than the WL participants. As for the DBAS (i.e., insomnia dysfunctional beliefs and attitudes), 
both the total score and subscale scores decreased after the intervention. By contrast, no differences between groups were observed in sleep quality, sleeplessness, and emotional symptoms (i.e. anxiety and depression) in the post-treatment scores.

Within-group comparisons (i.e., pre- and post-test assessment) indicated that the participants in the CBT- $\mathrm{i}$ improved on all post-treatment measures in comparison with the pre-treatment scores, except on the DBAS-causal attributions subscale. As expected, the WL participants scored similarly on the pre- and post-treatment measures, with one exception: the number of situations in which the subject indicated that sleeplessness was lower at post-treatment than at pre-treatment.

Table 2. Differences between groups (WL vs CBT-i) and within groups (pre and post-treatment) on both insomnia and emotional symptoms dimensions

\begin{tabular}{|c|c|c|c|c|c|c|c|c|c|c|}
\hline \multirow{2}{*}{ Dimensions } & \multicolumn{2}{|c|}{ Pre-treatment } & \multicolumn{2}{|c|}{ Post-treatment } & \multicolumn{2}{|l|}{ Time } & \multicolumn{2}{|c|}{ Sample group } & \multicolumn{2}{|c|}{$\begin{array}{l}\text { Time } \mathrm{x} \\
\text { group }\end{array}$} \\
\hline & $\begin{array}{c}\text { WL } \\
(n=21)\end{array}$ & $\begin{array}{c}\text { CBT-i } \\
(n=17)\end{array}$ & $\begin{array}{c}\text { WL } \\
(n=21)\end{array}$ & $\begin{array}{c}\text { CBT-i } \\
(n=17)\end{array}$ & $F_{1,36}$ & $\eta^{2}$ & $F_{1,36}$ & $\eta^{2}$ & $F_{1,36}$ & $\eta^{2}$ \\
\hline $\begin{array}{l}\text { Severity of Insomnia } \\
\text { (ISI) }\end{array}$ & $17.61(3.20)$ & $17.76(3.17)^{1}$ & $15.76(3.96)^{\mathrm{a}}$ & $6.70(4.95)^{\mathrm{b} / 2}$ & $88.225^{* * *}$ & .710 & $17.816^{* * *}$ & .331 & $44.779 * * *$ & .554 \\
\hline Sleep quality (PSQI) & $13.09(4.42)$ & $13.35(3.51)^{1}$ & $11.66(2.65)$ & $10.28(5.28)^{2}$ & $15.477 * * *$ & .301 & 1.208 & - & $.041 *$ & .111 \\
\hline Sleeplessness (EES) & $7.14(4.01)^{1}$ & $5.41(2.95)^{1}$ & $1.33(1.11)^{2}$ & $.76(1.09)^{2}$ & $105.923 * * *$ & .746 & 2.695 & - & 1.309 & - \\
\hline $\begin{array}{l}\text { DBAS-Beliefs } \\
\text { and attitudes } \\
\text { (Total score) }\end{array}$ & $99.33(14.93)$ & $101.11(12.24)^{1}$ & $96.71(12.08)^{\mathrm{a}}$ & $124(16.28)^{\mathrm{b} / 2}$ & $29.583 * * *$ & .451 & $12.366^{* * *}$ & .256 & $46.743 * * *$ & .565 \\
\hline $\begin{array}{l}\text { Consequences } \\
\text { of insomnia } \\
\text { (DBAS) }\end{array}$ & $20.95(6.08)$ & $22.35(5.87)^{1}$ & $22.09(5.25)^{\mathrm{a}}$ & $29.11(6.65)^{\mathrm{b} / 2}$ & $18.081 * * *$ & .334 & $6.098^{*}$ & .145 & $9.139 * *$ & .202 \\
\hline $\begin{array}{l}\text { Control of sleep } \\
\text { (DBAS) }\end{array}$ & $30.8(15.54)$ & $29.29(5.69)^{1}$ & $27.95(6.24)^{\mathrm{a}}$ & $36.88(6.09)^{\mathrm{b} / 2}$ & 2.167 & - & 1.867 & - & $10.565^{* *}$ & .227 \\
\hline $\begin{array}{l}\text { Sleep expectations } \\
\text { (DBAS) }\end{array}$ & $10.19(2.18)$ & $9.88(1.69)^{1}$ & $9.95(1.88)^{\mathrm{a}}$ & $13.29(1.49)^{\mathrm{b} / 2}$ & $13.965 * * *$ & .280 & $12.398 * * *$ & .256 & $18.471 * * *$ & .339 \\
\hline $\begin{array}{l}\text { Causal attributions } \\
\text { (DBAS) }\end{array}$ & $8.28(1.48)$ & $8.41(1.22)$ & $7.85(1.51)^{\mathrm{a}}$ & $8.82(1.13)^{\mathrm{b}}$ & .001 & - & 2.298 & - & 2.507 & - \\
\hline $\begin{array}{l}\text { Sleep-promoting } \\
\text { practices (DBAS) }\end{array}$ & $31.61(5.08)$ & $31.05(4.13)^{1}$ & $30.09(4.70)^{\mathrm{a}}$ & $36.41(3.24)^{b / 2}$ & $6.655^{*}$ & .156 & $5.455^{*}$ & .132 & $21.465 * * *$ & .374 \\
\hline Depression (BDI) & $10.38(10.79)$ & $11.11(9.55)^{1}$ & $8.61(8.42)$ & $6.58(7.85)^{2}$ & $9.771 * *$ & .003 & .051 & - & 1.891 & - \\
\hline Anxiety (BAI) & $6.9(6.24)$ & $8.94(7.62)^{1}$ & $6.09(5.31)$ & $5.88(6.93)^{2}$ & $5.698^{*}$ & .137 & .216 & - & 1.927 & - \\
\hline
\end{tabular}

Note. Data are means (SD). Superscripts a.b. indicate between-group differences (control vs treatment). Superscripts ${ }^{1.2}$ indicate post-hoc within-group (pre vs post-treatment) $*^{* *} p<.001 ; * * p<.005$; ${ }^{*} p<.05$. WL: waiting list; CBT-i: cognitive-behavioral therapy for insomnia; ISI: Insomnia Severity Index; PSQI: Pittsburgh Sleep Quality Index; EES: Epworth Sleepiness Scale; DBAS: Dysfunctional Beliefs and Attitudes about Sleep Scale; BDI: Beck Depression Inventory; BAI: Beck Anxiety Inventory.

\section{Discussion}

To the best of our knowledge, this is the first study to examine the efficacy of CBT-i in the Spanish population. Our results support the efficacy of a group intervention for patients receiving care in the Spanish National Health System. This result coincides with Davidson et al. (2019), who demonstrated the real-world effectiveness of a CBT-i group program in an interdisciplinary Primary Care setting. The findings are also consistent with empirical evidence that supports CBT as the treatment of choice» for insomnia disorder (Brasure et al., 2016; Qaseem et al., 2016; Riemann et al., 2017). Main effects were found on insomnia severity, sleep quality, and insomnia-related dysfunctional beliefs and attitudes. The improvement observed in these cognitions is consistent with current 
cognitive models for insomnia, which postulate that dysfunctional beliefs and their affective valence may be specific mediating factors in insomnia (e.g., Harvey, 2002; Morin et al., 1993; Perlis et al., 2009). They may support sleep-disruptive habits and conditioned emotional responses that interfere with normal sleep (Edinger \& Means, 2005). The results suggest the benefits of including treatment components that focus on insomnia-related dysfunctional beliefs and attitudes. Nonetheless, the specific effects of CBT-i on these dimensions need to be further examined. Finally, the fact that participants in the WL and CBT-i groups score similarly in quality of sleep after the intervention is an unexpected result. This could be explained by the components of sleep that the PSQI assess, which only includes one item describing the subjective quality of sleep. Further studies should include other collection methods, such as interviews or daily reports, to assess more in depth both quantitative and qualitative aspects of sleep.

Sleeplessness and emotional symptoms also decreased after the treatment, but these findings could not be directly attributed to the intervention. The fact that the participants in the WL group showed less sleeplessness after the treatment was a discordant result. It could be due to the expectations of the patients on the waiting list, external factors (i.e., life events), or the characteristics of the sleeplessness self-report, which only assesses the number of situations in which the individuals fall asleep. By contrast, the improvement observed in emotional symptoms in the CBT- $\mathrm{i}$ group is consistent with the meta-analysis by Ballesio et al. (2018), which found that CBT-i improved depressive symptoms in insomnia patients. These findings also coincide with Harvey (2002), who suggested that insomnia-related dysfunctional beliefs and attitudes could be a maintenance factor for excessive mental activity (i.e., worry), which is associated with an increase in physiological activation and distress. From this perspective, an intervention that focuses on these cognitions could help to reduce negative mental activity and, thus, contribute indirectly to diminishing emotional symptoms. As several authors note (e.g., Borsboom, 2017; Harvey, 2009), insomnia could operate transdiagnostically across and within diagnostic categories, suggesting that CBT-i interventions could help to prevent other psychopathologies, such as emotional disorders. Nonetheless, we have to be cautious when interpreting these results because of our sample's characteristics: patients with primary insomnia disorder with no comorbidities and low levels of emotional symptoms.

In sum, these findings support the efficacy of a group CBT-i protocol for patients with primary insomnia disorder, and they suggest a key role of insomnia-related dysfunctional beliefs and attitudes in perpetuating insomnia.
Several study limitations should be mentioned. First, the sample was composed of a relatively small number of patients. Although the characteristics of the sample (i.e., primary insomnia disorder, no comorbid diagnosis) are adequate, in order to generalize the data obtained, studies with larger sample sizes should be carried out. Another limitation was the use of a waiting list group. Lastly, we found low internal consistency for some of the DBAS subscales, similar to what was found in previous studies in the Spanish-speaking population (e.g. Sierra et al., 2005). Although the internal consistency of the total score was adequate, future studies should include other data collection methods.

Limitations notwithstanding, CBT-i is an effective intervention for primary insomnia. Its implementation in a group format could help guarantee its accessibility for patients in the Spanish National Health System. Future randomized controlled trials should further investigate the efficacy of the treatment and examine long-term effects.

\section{Conflicts of interest}

The authors have no conflicts of interest to declare.

\section{References}

Ashworth, D. K., Sletten, T. L., Junge, M., Simpson, K., Clarke, D., Cunnington, D., \& Rajaratnam S. M. (2015) A randomized controlled trial of cognitive behavioral therapy for insomnia: an effective treatment for comorbid insomnia and depression. Journal of Counseling Psychology, 62, 115-123. http://doi. org/ 10.1037/cou0000059.

Baglioni, C., Altena, E., Bjorvatn, B., Blom K., Bothelius K.; Devoto, A., Espie, C. A., Ftrase, L., Gavriloff, D., Tuuliki, H., Hoflehner, A., Högl, B., Hozinger, B., Járnefelt, H., Jernelöv, S., Johann, A. F., Lombardo, C., Nissen, C., Palagini, L., ... \& Riemann, D. (2019). The European academy for cognitive behavioural therapy for insomnia: An initiative of the European Insomnia Network to promote implementation and dissemination of treatment. Journal of Sleep Research, 29(2), e12967, 1-29. http://doi.org/10.1111/jsr.12967.

Baglioni, C., Battagliese, G., Feige, B., Spiegelhalder, K., Nissen, C., Voderholzer, U., Lombardo, C., \& Riemann, D. (2011). Insomnia as a predictor of depression: a meta-analytic evaluation of longitudinal epidemiological studies. Journal of Affective Disorders, 135(1-3), 10-19. http://doi.org/10.1016/j. jad.2011.01.011.

Ballesio, A., Aquino, M. R. J. V., Feige, B., Johann, A. F., Kyle, S. D., Spiegelhalder, K., Lombardo, C., Rücker, G., Riemann, D., \& Baglioni, C. (2018). The effectiveness of behavioural and cognitive behavioural therapies for insomnia on depressive and fatigue symptoms: a systematic review and network meta-analysis. Sleep Medicine Reviews, 37, 114-129. http:// doi.org/10.1016/j.smrv.2017.01.006. 
Bastien, C. H., Vallières, A., \& Morin, C. M. (2001). Validation of the Insomnia Severity Index as an outcome measure for insomnia research. Sleep Medicine, 2(4), 297-307. http://doi. org/10.1016/S1389-9457(00)00065-4.

Beck, A. T., \& Steer, R. A. (1993). Beck Anxiety Inventory. Psychological Corporation: San Antonio, TX.

Beck, A. T., Steer, R. A., \& Brown, G. (1996). Manual for the Beck Depression Inventory-II, Psychological Corporation: San Antonio, TX.

Borsboom, D. (2017). A network theory of mental disorders. World Psychiatry, 16(1), 5-13. http://doi.org/10.1002/wps.20375.

Brasure, M., Fuchs, E., MacDonald, R., Nelson, V. A., Koffel, E., Olson, C.M., Khawaja, I. S., Diem, S., Carlyle, M., Wilt, T. J., Oullette, J., Butler, M, \& Kane, R. L. (2016). Psychological and behavioral interventions for managing insomnia disorder: An evidence report for a clinical practice guideline by the American College of Physicians. Annals of Internal Medicine, 165(2), 113-124. http://doi.org/10.7326/M15-1782.

Buysse, D. J., Reynolds, C. F., Monk, T. H., Berman, S. R., \& Kupfer, D. J. (1989). The Pittsburgh Sleep Quality Index: a new instrument for psychiatric practice and research. Psychiatry Research, 28(2), 193-213. https://doi.org/10.1016/0165-1781(89)90047-4.

Davidson, J. R., Dawson, S., \& Krsmanovic, A. (2019). Effectiveness of group cognitive behavioral therapy for insomnia (CBT-I) in a primary care setting. Behavioral Sleep Medicine, 17(2), 191-201. https://doi.org/10.1080/15402002.2017.1318753.

Edinger, J. D., Fins, A. I., Glenn, D. M., Sullivan, R. J., Jr., Bastian, L. A., Marsh, G. R., Dailey, D., Hope, T. V., Young, M., Shaw, E., \& Vasilas, D. (2000). Insomnia and the eye of the beholder: are there clinical markers of objective sleep disturbances among adults with and without insomnia complaints?. Journal of Consulting and Clinical Psychology, 68(4), 586-593. http:// doi.org/10.1037/0022-006X.68.4.586.

Edinger, J. D., \& Means, M. K. (2005). Cognitive-behavioral therapy for primary insomnia. Clinical Psychology Review, 25(5), 539-558. http://doi.org/10.1016/j.cpr.2005.04.003.

Edinger, J. D., Wohlgemuth, W. K., Radtke, R. A., Marsh, G. R., \& Quillian, R. E. (2001). Cognitive behavioral therapy for treatment of chronic primary insomnia: a randomized controlled trial. Jama, 285(14), 1856-1864. http://doi.org/10.1001/jama.285.14.1856.

Franzen, P. L., \& Buysse, D. J. (2008). Sleep disturbances and depression: Risk relationships for subsequent depression and therapeutic implications. Dialogues in Clinical Neuroscience, 10(4), 473-481. http://doi.org/PMC3108260.

Gee, B., Orchard, F., Clarke, E., Joy, A., Clarke, T., \& Reynolds, S. (2019). The effect of non-pharmacological sleep interventions on depression symptoms: A meta-analysis of randomised controlled trials. Sleep Medicine Reviews, 43, 118-128. http:// doi.org/10.1016/j.smrv.2018.09.004.

Geiger-Brown, J. M., Rogers, V. E., Liu, W., Ludeman, E. M., Downton, K. D., \& Diaz-Abad, M. (2015). Cognitive behavioral therapy in persons with comorbid insomnia: A meta-analysis. Sleep Medicine Reviews, 23, 54-67. http://doi.org/10.1016/j.smrv.2014.11.007.

Harvey, A. G. (2002). A cognitive model of insomnia. Behaviour Research and Therapy, 40(8), 869-894. http://doi.org/10.1016/ s0005-7967(01)00061-4.

Harvey, A. G. (2009). A transdiagnostic approach to treating sleep disturbance in psychiatric disorders. Cognitive Behaviour Therapy, 38(S1), 35-42. http://doi.org/10.1080/16506070903033825.
Johns, M. W. (1991). A new method for measuring daytime sleepiness: the Epworth Sleepiness Scale. Sleep, 14(6), 540-545. http://dx.doi.org/10.1093/sleep/14.6.540.

Qaseem, A., Kansagara, D., Forciea, M. A., Cooke, M., \& Denberg, T. D. (2016). Management of chronic insomnia disorder in adults: a clinical practice guideline from the American College of Physicians. Annals of Internal Medicine, 165(2), 125-133. http://doi.org/10.7326/M15-2175

Morin, C. M. (1994). Dysfunctional Beliefs and Attitudes about Sleep: Preliminary scale development and description. The Behavior Therapist, 17, 163-164.

Morin, C. M., Blais, F., \& Savard, J. (2002). Are changes in beliefs and attitudes about sleep related to sleep improvements in the treatment of insomnia? Behaviour Research and Therapy, 40(7), 741-752. http://doi.org/10.1016/S0005-7967(01)00055-9.

Morin, C. M., LeBlanc, M., Daley, M., Grégoire, J. P., \& Merette, C. (2006). Epidemiology of insomnia: prevalence, self-help treatments, consultations, and determinants of help-seeking behaviors. Sleep Medicine, 7(2), 123-130. http://doi.org/10.1016/j. sleep.2005.08.008.

Morin, C. M., Stone, J., Trinkle, D., Mercer, J., \& Remsberg, S. (1993). Dysfunctional beliefs and attitudes about sleep among older adults with and without insomnia complaints. Psychology of Aging, 8(3), 463-467. http://doi.org/10.1037/0882-7974.8.3.463.

Ohayon, M. M. (2002). Epidemiology of insomnia: what we know and what we still need to learn. Sleep Medicine Reviews, 6(2), 97-111. http://doi.org/10.1053/smrv.2002.0186.

Perlis, M. L., Jungquist, C., Smith, M. T. \& Posner, D. (2009). Insomnio: una guía cognitivo-conductual de tratamiento. Desclée de Brower: Bilbao.

Pituch, K. A., \& Stevens, J. P. (2015). Applied multivariate statistics for the social sciences: Analyses with SAS and IBM's SPSS. Routledge: New York and London.

Riemann, D., Baglioni, C., Bassetti, C., Bjorvatn, B., Groselj, L. D., Ellis, J. G., Espie, C. A., Garcia-Borreguero, D., Gjerstad, M., Gonçalves, M., Hertenstein, R., Jansson-Fröjmark, M., Jennum, P. J., Leger, D., Nissen, C., Parrino, L., Paunio, T., Pevernagie, D., Verbraecken, J., .. \& \& Spiegelhalder K. (2017). European guideline for the diagnosis and treatment of insomnia. Journal of Sleep Research, 26(6), 675-700. http:// doi.org/10.1111/jsr.12594.

Sadler, P., McLaren, S., Klein, B., Harvey, J., \& Jenkins, M. (2018). Cognitive behavior therapy for older adults with insomnia and depression: a randomized controlled trial in community mental health services. Sleep, 41(8), 1-12 http:// doi.org/10.1093/sleep/zsy104.

Sheehan, D. V., Lecrubier, Y., Sheehan, K. H., Amorim, P., Janavs, J., Weiller, E., Hergueta, T., Baker, R., \& Dunbar, G. C. (1998). The Mini-International Neuropsychiatric Interview (M.I.N.I): The development and validation of a structured diagnostic psychiatric interview for DSM-IV and ICD-10. The Journal of Clinical Psychiatry, 59, 22-33. http://doi.org/9881538.

Sierra, J. C., Delgado-Domínguez, C. J., y Carretero-Dios, H. (2005). Propiedades psicométricas de la Dysfunctional Beliefs and Attitudes about Sleep scale (DBAS) en una muestra española de sujetos normales [Psychometric properties of the Dysfunctional Beliefs and Attitudes about Sleep scale (DBAS) in a Spanish sample of normal subjects]. Revista Latinoamericana de Psicología, 37(3), 523-539. http://doi.org/10481/32661. 
van Straten, A., van der Zweerde, T., Kleiboer, A., Cuijpers, P., Morin, C. M., \& Lancee, J. (2018). Cognitive and behavioral therapies in the treatment of insomnia: A meta-analysis. Sleep Medicine Reviews, 38, 3-16. http://doi.org/10.1016/j.smrv.2017.02.001

Wilson, S. J., Nutt, D. J., Alford, C., Argyropoulos, S. V., Baldwin, D. S., Bateson, T. C., Britton, A. N., Crowe, C., Dijk, D. J., Espie, C.
A., Gringras, P., Hajak, G., C Idzikowski, C., Krystal, C. A., Nash, J. R., Selsick, H., Sharpley, A. L., Wade, A. G. (2010). British Association for Psychopharmacology consensus statement on evidence-based treatment of insomnia, parasomnias and circadian rhythm disorders. Journal of Psychopharmacology, 24(11),1577-1601. http://doi.org/10.1177/02698811103793. 